\title{
Antoon De Baets, Crimes against History (Londres: Routledge, 2019), 186 págs.
}

En los últimos años, diversas partes del mundo se han visto sacudidas por una según algunos autores- "tercera ola autoritaria" protagonizada por partidos y movimientos políticos que han aprovechado la crisis de las democracias liberales (económica y política fundamentalmente) para crecer exponencialmente mediante un discurso abiertamente populista, marcadamente nacionalista y que, en esencia, ha planteado una amenaza para ciertos espacios de libertad de expresión. ${ }^{1}$ En Europa, este tipo de partidos han conseguido llegar al gobierno en Hungría, Polonia y Austria -sin entrar en el caso ruso-, mientras que fuera del Viejo Continente países como Brasil o Estados Unidos -aunque este en menor medida- serían ejemplos de esta "alternativa" a unas democracias liberales que, según predijo atrevida y erróneamente Francis Fukuyama tras el colapso de la Unión Soviética, iban a erigirse como el ordenamiento sociopolítico definitivo que marcaría el "fin de la Historia". ${ }^{2}$ Todos estos gobiernos, partidos y movimientos hacen un uso extensivo de un chovinismo exacerbado que ejerce como espina dorsal de todo su discurso político, ya que las narrativas del "America first!", adaptadas a cada escenario particular, justifican su incursión ultraconservadora, regresiva en no pocos casos, en materias como la inmigración o los derechos sociales. Así, ese chovinismo ha alimentado la gestación de nuevos Sonderwegs que han buscado destilar las esencias inmutables que harían única a cada una de estas naciones, algo en lo que la Historia juega, como no podía ser de otro modo y como ha sido desde siempre, un papel esencial. La ley impulsada por el gobierno polaco, finalmente retirada ante la presión internacional, que impedía vincular al país con el Holocausto, prohibiendo expresiones como "campos de concentración polacos"; o las protestas de activistas de extrema derecha e historiadores ucranianos ante la publicación de una biografía del líder nacionalista Stepán Bandera -vinculado con el asesinato de judíos y polacos durante la Segunda Guerra Mundial-, que incluso obligaron a suspender una serie de conferencias que su autor, el historiador Grzegorz Rossoliński-Liebe, iba a dar en varias ciudades del país, son solo dos ejemplos de esa instrumentalización de la Historia, que no solo tiene que ver con la propia tergiversación de los hechos sino que fundamentalmente se canaliza a través de la persecución de toda libertad de expresión que pueda contraponerse a la revisión del pasado. ${ }^{3}$ Algo que, como vemos, vuelve a ganar terreno en nuestros días, pero que bebe de la, por así decirlo, mejor tradición de las dictaduras, autoritarismos, reinos e imperios que se han sucedido a lo largo de la historia de la Humanidad.

Es aquí precisamente donde el historiador berlga Antoon de Baets sitúa su Crimes against History. El libro constituye un intento de teorización, todavía en fase embrionaria, en torno a lo que significativamente de Baets denomina como "crímenes

\footnotetext{
${ }^{1}$ Esa idea de la "tercera ola autoritaria" en Anna Lührmann y Staffan I. Lindberg, "A third wave of autocratization is here: what is new about it?", Democratization, 26,7 (2019), 1095-1113.

${ }^{2}$ Eckart Woertz, "El populismo en Europa: ¿de síntoma a alternativa?", CIDOB Report, 1 (2017), disponible

https://www.cidob.org/es/publicaciones/serie_de_publicacion/cidob_report/cidob_report/el_populismo_e n_europa_de_sintoma_a_alternativa [consultado por última vez el 30/11/2019].

Véanse https://www.washingtonpost.com/news/worldviews/wp/2018/06/27/polands-holocaust-lawcaused-an-outcry-now-in-a-surprise-its-being-largely-reversed/; y Grzegorz Rossoliński-Liebe, Stepan Bandera. The Life and Aftermath of a Ukrainian Nationalist. Fascism, Genocide and Cult (Stuttgart: Ibidem Press, 2014), X.
} 
contra la Historia", adentrándose en sus motivaciones y casuísticas dentro de un amplio marco cronológico que discurre desde la Antigüedad hasta nuestros días. De este modo, Crimes against History profundiza en una línea de trabajo e investigación, que ha definido en buena medida la carrera de de Baets, centrada en los abusos cometidos contra la disciplina histórica y contra la libertad de expresión, con títulos como Responsible History (New York, Oxford: Berghahn Books, 2009) o Censorship of Historical Thought: A World Guide 1945-2000 (London: Greenwood Press, 2002). No obstante, pese a que Crimes against History es una continuación evidente de trabajos anteriores de de Baets, el propio autor admite el carácter inicial de la investigación y la taxonomía que presenta (p. 13). Esto queda evidenciado, como luego detallaré más extensamente, en la superficialidad con la son abordados la mayoría de los países, a excepción quizá de la Alemania nazi y la Unión Soviética, que cuentan con una bibliografía más amplia y extensa en torno a este tipo de cuestiones.

La obra de Antoon de Baets se estructura en dos partes. En la primera de ellas el autor construye la definición de los sujetos de los que se ocupa el estudio, que califica como "productores de historia", para después hacer un recorrido por las diferentes formas que han adoptado esos "crímenes contra la historia". Así, los dos primeros capítulos se centran en los historiadores y archivistas perseguidos, represaliados, encarcelados, o directamente asesinados debido a su profesión, es decir, por su posición como académicos, por su compromiso político con unas determinadas ideas, por su propio trabajo investigador, por su voluntad de preservar documentos $\mathrm{u}$ otros testimonios pertenecientes a grupos objetivo de procesos eliminacionistas -caso de los judíos bajo el Tercer Reich-, o por ser ellos mismos miembros de dichos grupos. El tercer capítulo aborda un mecanismo de censura más sutil pero igualmente efectivo, como es el de la difamación pública como forma de presión dirigida hacia intelectuales y académicos que, con sus interpretaciones, contradicen las líneas oficiales marcadas por gobiernos y regímenes sobre los distintos pasados nacionales o acerca de determinadas figuras históricas. El cuatro trata los "crímenes contra la historia" desde la perspectiva de la cultura material, es decir, ahondando en las prácticas iconoclastas desplegadas por determinados gobiernos y regímenes con el objetivo de ofrecer unas visiones homogéneas tanto de la propia nación como de su pasado; mientras que el quinto se centra en una cuestión muy en boga en el mundo de hoy en día, dominado por lo que se ha venido a denominar como la "post-verdad", como las fake news, en este caso aplicadas a la Historia. Por su parte, la segunda parte de la obra describe las distintas formas de resistencia adoptadas por historiadores y otros intelectuales frente a la censura a las que se han visto sometidos, unas prácticas que van tanto desde lo puramente discursivo hasta la militancia política o la preservación de obras prohibidas.

De entre todos los países en los que de Baets identifica este tipo de prácticas de censura contra la Historia, el Iraq anterior y posterior a Sadam Hussein, la Alemania nazi, y especialmente la Unión Soviética son los que acumulan más casos. En buena medida, esto se debe a la superficialidad en la selección de fuentes a la que antes aludía, que sin duda confirma lo ya planteado por el propio autor respecto al carácter embrionario del trabajo, pero que al mismo tiempo constituye un problema para el planteamiento del mismo. Por ejemplo, para algunos países como Argentina o España solo se menciona una única fuente, cuando en ambos casos existe una amplia literatura sobre la represión en diversos ámbitos, incluido el mundo intelectual vinculado a la disciplina histórica. De hecho, para España resulta imprescindible acudir a la obra de Jaume Claret, El atroz desmoche, que sin embargo no está referenciada en el trabajo de 
de Baets. En cierto modo, parece que la identificación de las diversas casuísticas dependiese más de la particular selección o conocimiento de las fuentes por parte del autor que de un análisis sistemático. Bien es cierto que esto resulta complejo en un trabajo con un enfoque tan amplio geográfica y cronológicamente, y que de Baets admite estos límites en su libro, pero no por ello es menos importante señalarlo, ya que una mayor dedicación a casos donde la bibliografía es medianamente accesible hubiese, a buen seguro, enriquecido los detallados análisis que se van construyendo en cada uno de los capítulos.

En cualquier caso, pese al impacto sobre el detalle en el análisis de las diferentes casuísticas, es muy reseñable la voluntad de de Baets de plantear un estudio interépocas y con un enfoque eminentemente global. Desde hace algunos años, la irrupción de este paradigma metodológico ha permitido replantearse cuestiones ya abordadas a través de perspectivas más amplias que incorporan un mayor número de casos de los que habitualmente se manejan. Esto, potenciado con la larga duración que de Baets confiere a su trabajo mediante el análisis de esos "crímenes contra la Historia" desde la Antigüedad, posibilita ahondar en las continuidades y discontinuidades, similitudes y diferencias, existentes entre periodos cronológicos y ámbitos geográficos. Por ejemplo, una cuestión central como la violencia, que tiene un papel protagónico en Crimes against History, adquiere una dimensión mucho más rica, poliédrica y, sobre todo, contextual y contingente. De Baets identifica como las motivaciones más recurrentes en la persecución sufrida por los "productores de historia" la de índole política, nacional y religiosa, que sin embargo suelen discurrir paralelas o incluso alternarse en el mismo episodio, lo que complejiza la compresión de estos fenómenos de violencia. Además, la incorporación del enfoque global, es decir de escenarios más allá de las fronteras occidentales, permite refinar las interpretaciones y, además, dotarlas de un fundamento mucho más solvente. No en vano, pensemos en el modo en que se ha construido un concepto capital como el de "guerra total", generalmente en base a la disección de conflictos acontecidos en Europa o Estados Unidos pero sin penas apenas tener en cuenta la miríada de guerras desarrolladas en el Sur global o en China, en no pocos casos de una mayor complejidad y mortalidad. Así, más allá de la propia teorización que plantea de Baets, su apuesta por un enfoque global hace de su trabajo un referente insoslayable, y en buena medida un ejemplo para una historiografía como la española, que suele tardar en incorporar, al menos de forma generalizada, las metodologías más punteras de la disciplina histórica.

En conclusión, la importancia de Crimes against History radica en su incursión en un tema que no ha sido apenas explorado como tal, la cual además discurre por unos caminos metodológicos y de definición conceptual extremadamente precisos. En este sentido, la obra de de Baets no es sino el punto de partida de ulteriores investigaciones que pueden, sobre la base de la taxonomía sugerida en el libro, descender al detalle de los casos de estudio concretos, paliando así esa problemática que señalaba antes respecto a la escasez de fuentes. Al mismo tiempo, Crimes against History es un libro necesario en el mundo de hoy en día. La irrupción de esa "tercera ola autoritaria", aunque no exclusivamente, ha llevado aparejado un cuestionamiento de valores esenciales como la libertad de expresión, la democracia o el derecho a la información, al tiempo que ha exacerbado la utilización de la Historia como un arma de exclusión, diferenciación y señalamiento. Por ello, el trabajo de de Baets no es sino una forma de militancia política y social, un compromiso que debe servir de ejemplo para el resto de historiadores, académicos e intelectuales. La libertad de expresión es un bien 
sumamente preciado al tiempo que frágil, por lo que su preservación pasa por no abandonar el combate contra aquellos que buscan instrumentalizar el pasado, en este caso, en beneficio propio y en nombre de principios pretendidamente superiores como la nación o la religión. No en vano, es la propia Historia la que nos señala el peligro potencial que puede tener el transitar un camino como ese.

Miguel Alonso Ibarra

Universitat Autònoma de Barcelona (UAB)

miguel.alonso.ibarra@gmail.com

Fecha de recepción: 8 de octubre de 2019.

Fecha de aceptación: 5 de diciembre de 2019.

Publicación: 31 de diciembre de 2019

Para citar este artículo: Miguel Alonso Ibarra, "Antoon De Baets, Crimes against History (Londres: Routledge, 2019), 186 págs.”, Historiografías, 18 (julio-diciembre, 2019): pp. 127-130. 